\title{
From the Editor-in-Chief's Desk: Continuing the Discussion on Sustainability and Work
}

\author{
Margaret H. Vickers
}

Published online: 15 December 2009

(C) Springer Science+Business Media, LLC 2009

Employee Responsibilities and Rights Journal broke new ground in the previous issue when attention was drawn to the plight of marginalized groups of workers, especially through discussions about sustainability and organizational social responsibility. ${ }^{1}$ However, determinations as to who is responsible, for what, and to whom remain obscure, especially when it comes to improved employment outcomes and especially for disadvantaged and marginalized groups. Sustainability and organizational social responsibility doctrines have yet to articulate approaches to classifying, prioritizing, and understanding the diverse needs of an organization's multiple stakeholders (Fenwick and Bierema 2008) and, despite growing business use of the term "sustainability," some are claiming that, so far, little has been achieved in changing organizational practices to effect real change (Fenwick and Bierema 2008).

Dexter Dunphy (2003) asked why debates and discussions about sustainability and organizational social responsibility are not currently raging in business schools around the world (my emphasis). I agree they are not and ask more specifically: Why isn't there more attention being paid to questions around sustainability and work? When I hear about sustainability, I learn about the environment, the planet, global warming, the need for clean air, the protection of our precious water resources, as well as the growing numbers of endangered species of flora and fauna. In short, we are continually reminded that we shouldn't overdo things or plunder that which surrounds us, so there is some stuff left for those who come after us. Good advice, but what about the sustainability of employment to support workers and their future jobs?

\footnotetext{
${ }^{1}$ I deliberately refrain from using the term Corporate Social Responsibility (CSR), as others have done, because use of this term perpetuates the view that it is somehow only the responsibility of large private corporations to be socially responsible, especially when it comes to producing sustainable work options for their employees. I don't agree. Small and medium private enterprises are equally responsible for being socially responsible and operating in sustainable ways, as are organizations in the public and not-for-profit sectors. Hence, I exercise my preference for and use of the alternative term "organizational social responsibility."
}

M. H. Vickers $(\bowtie)$

University of Western Sydney, Sydney, Australia

e-mail: m.vickers@uws.edu.au 
Concerns surrounding significant workplace and social groups are increasingly at the center of debates regarding sustainability (Jabbour and Santos 2008). These might include workers with disability or chronic illness, older workers, younger workers, workers who care for young children or aging relatives, workers with diverse sexual and religious preferences, and workers with varying ethnic and racial heritages, as well as those who may be identified as the "wrong" gender. The importance of managing a diverse workforce is increasingly gaining recognition and attention, even though such debates have been recognized as being, to date, rather narrowly focussed (Ogbonna and Harris 2006; Wooten 2008).

Multidimensional critical human resource management is needed in organizations that intend to operate in sustainable ways (Jabbour and Santos 2008). Sustainability is defined as development that meets the needs of the present without compromising the ability of future generations to meet their own needs (Wilkinson et al. 2001). Sustainability in organizations results in activities that extend the socially useful life of organizations, enhance the planet's capacity to maintain and renew itself, enhance society's ability to maintain itself while solving its major problems, and enable us to maintain a decent level of welfare for present and future generations (Dunphy 2003).

Importantly, sustainable workplaces also require an ethical dimension of fairness (Wilkinson et al. 2001). The sustainability of organizations means that we have to find ways to enable workers to keep working, especially those who find themselves working on and around the fringes. This means using more ethical and strategic human resource management which can, in turn, stimulate and support appropriate staff development (Jabbour and Santos 2008). Improving the work and social environments for workers is critical to improve employee commitment and organizational capacity-building and to ensure organizational systems become capable of regeneration and renewal (Wilkinson et al. 2001).

Some have argued that human resource management practices remain purely regulatory frameworks and technologies used to discipline employees into complying with limited and limiting notions as to what is considered "normal" (Fenwick 2001, 2005). In some organizational arenas, human hearts and souls continue to be treated as raw capital to be harnessed for organizational gain (Fenwick 2005). Human resources management critics claim that the effects of these cultural engineering practices and questionable ethics include an emphasis on employee deficits, repression of diversity, increased employee stress, and subjugated workers who find themselves increasingly controlled in ways that come to be viewed by those around them as utterly natural (Fenwick 2005).

More critical and sustainable human resource development requires innovation and practices that stimulate workers to think, create, and reflect in original ways about their workplaces and how things are done. Employee innovation is crucial to sustainability (Wilkinson et al. 2001; Jabbour and Santos 2008). Jabbour and Santos (2008) highlight that what is required of employees in sustainable workplaces is that they be innovative and original, and have highly developed skills and capacities in: (1) creativity; (2) long-term focus; (3) cooperative and interdependent behavior; and (4) high tolerance for ambiguity and unpredictability (see Jabbour and Santos 2008). There is also a growing strand of human resource development literature than calls for more socially conscious work practices that contribute to building more just, democratic, and sustainable workplaces (Fenwick and Bierema 2008). Indeed, some have claimed that many of our current policy solutions intended to address issues of social justice and democracy in organizations are nothing more than "empty shells" offering nothing of substance or value to those workers they are intended to support (Hoque and Noon 2004, p. 497). 
The way work is structured also continues to reflect and reproduce the hegemonic power of elite White able-bodied males (Harlan and Robert 1998). The systems of shared meaning in contemporary work organizations continue to be expressed in the rules, regulations, policies, and procedures that define expectations as to the way work is done and how the employment relationship is managed. These are the unremarkable aspects of bureaucracy in which we participate and include routine aspects of organization including hierarchy, authority, routinization, control, job descriptions, pay, policies, work schedules, and time and attendance rules (Harlan and Robert 1998). Such organizational and workplace norms underpin the continuing domination of elite groups over those less powerful. Unfortunately, employers, in large part, continue to ignore the possibilities for changing the social, cultural, and ethical organization of the workplace (Cockburn 1991; Harlan and Robert 1998). Further exploration of contemporary workplaces is required, including the ways in which societal and organizational transformations are shaping employee experiences and perceptions, especially in relation to issues of diversity and equality (Ogbonna and Harris 2006).

When thinking about workers, the most appropriate responses to questions of sustainability are those that address the way we do work and the way we think about work. Equally important is guaranteeing employees access to due process and a means to be heard by creating policies that stimulate the inclusion of issues concerning sustainability and internal relationships which promote mutual influence, mutual understanding, and mutual responsibility (Gollan 2005; Jabbour and Santos 2008). Gollan's (2005) High Involvement Management, for example, seeks to minimize differences and emphasize control and coordination based on shared goals and understandings that align with interests, expertise, and capacities, through the adoption of innovative work practices that encourage high employee involvement and worker commitment (Gollan 2005). High Involvement Management also requires high levels of trust between management and employees and assumes that workers can be trusted to make important workplace decisions that will result in greater productivity and effectiveness, and that they will be given opportunities to do this (Gollan 2005).

Organizations are increasingly being urged to find holistic, new, and innovative ways of thinking about the managerial challenges that confront them (Wilkinson et al. 2001), such as the need for sustained employment opportunities, particularly for disadvantaged groups. Managers have been urged to reconsider, for example, emancipatory action learning, critical reflection, reflexivity tools, and double-loop learning (see, for example, Fenwick 2005; Schein 1992). The increasing application of more critical approaches to doing work can enable workplace reforms that align with equity, justice, and organizational democracy. Critical approaches also recognize that knowledge is contested, political, and nonperformative, while engaging in workplace inquiry that is based on reflexivity and critical challenge (Fenwick 2005). Practices such as these that support more sustainable workplaces and work practices are essential (Wilkinson et al. 2001).

Without sustainable work and work practices, workers face a future of employment uncertainty. We know that persistent unemployment is central to financial hardship and has deleterious effects on self-confidence, competence, and social participation. Unemployment can also result in increased health problems, increased stress, and other deleterious physiological outcomes (Nettleton 1995; Argyle 1989). Paid work, on the other hand, is central to identity and financial independence (Bill et al. 2006). By making our workplaces and the way we think about doing work more sustainable, we can improve the working futures of many. However, more research is needed to produce sustainable work practices and working outcomes for workers to improve their social, cultural, personal, and financial 
futures. I encourage readers to engage with these and other work and sustainability questions when considering future submissions to this journal.

In closing on a positive note, it is with much delight that I turn to recent evidence of the increasing success and sustainability of Employee Responsibilities and Rights Journal. Readers and authors will be gratified to learn, as I was, that the journal's usage level over the period of June 2008 to June 2009 has almost quadrupled. We all-readers, authors, editors, and Editorial Board members - should be very pleased and proud to learn that what is being published in Employee Responsibilities and Rights Journal is being tremendously well received by the academic and practitioner community worldwide. Please keep sending in your ideas, articles, book reviews, comments, and plans for special issues. And I would also love to hear what you think about the new cover design. Enjoy this first issue for 2010.

\section{References}

Argyle, M. (1989). The social psychology of work (2nd ed.). London: Penguin Books.

Bill, A., Cowling, W. M., \& Quirk, V. (2006). Employment programs for people with psychiatric disability: the case for change. Australian Journal of Social Issues, 42(2), 209-220.

Cockburn, C. (1991). In the way of women: Men's resistance to sex equality in organizations. New York: ILR.

Dunphy, D. (2003). Corporate sustainability: challenge to managerial orthodoxies. Journal of the Australian and New Zealand Academy of Management, 8(2), 2-11.

Fenwick, T. (2001). Questioning the learning organization. In C. Parrie \& D. Scott (Eds.), Knowledge, power and learning (pp. 74-88). London: Sage/Paul Chapman.

Fenwick, T. (2005). Conceptions of critical HRD: dilemmas for theory and practice. Human Resource Development International, 8(2), 225-238.

Fenwick, T., \& Bierema, L. (2008). Corporate social responsibility: issues for human resource development professionals. International Journal of Training and Development, 12(1), 24-35.

Gollan, P. J. (2005). High involvement management and human resource sustainability: the challenges and opportunities. Asia Pacific Journal of Human Resources, 43(1), 18-33.

Harlan, S. L., \& Robert, P. M. (1998). The social construction of disability in organizations: why employers resist reasonable accommodation. Work and Occupations, 25(4), 397-435.

Hoque, K., \& Noon, M. (2004). Equal opportunities policy and practice in Britain: evaluating the "empty shell" hypothesis. Work, Employment and Society, 18(3), 481-506.

Jabbour, C. J. C., \& Santos, F. C. A. (2008). The central role of human resource management in the search for sustainable organizations. The International Journal of Human Resource Management, 19(12), 2133-2154.

Nettleton, S. (1995). The sociology of health and illness. Cambridge: Polity.

Ogbonna, E., \& Harris, L. C. (2006). The dynamics of employee relationships in an ethnically diverse workforce. Human Relations, 59(3), 379-407.

Schein, E. H. (1992). Organizational culture and leadership (2nd ed.). San Francisco: Jossey-Bass.

Wilkinson, A., Hill, M., \& Gollan, P. (2001). The sustainability debate. International Journal of Operations and Production Management, 21(12), 1492-1502.

Wooten, L. P. (2008). Guest editor's note: breaking barriers in organizations for the purpose of inclusiveness. Human Resource Management, 47(2), 191-197. 